\title{
ROUTING CORNERS OF BUILDING STRUCTURES - BY THE METHOD OF VECTOR ADDITION - MEASURED WITH RTN GNSS SURVEYING TECHNOLOGY
}

\author{
Robert Krzyżek \\ AGH University of Science and Technology, \\ Faculty of Mining Surveying and Environmental Engineering, \\ Department of Geomatics \\ 30 Mickiewicza Al., 30-059 Krakow, Poland \\ e-mail: rkrzyzek@agh.edu.pl
}

\begin{abstract}
The paper deals with the problem of surveying buildings in the RTN GNSS mode using modernized indirect methods of measurement. As a result of the classical realtime measurements using indirect methods (intersection of straight lines or a point on a straight line), we obtain a building structure (a building) which is largely deformed. This distortion is due to the inconsistency of the actual dimensions of the building (tie distances) relative to the obtained measurement results. In order to eliminate these discrepancies, and thus to ensure full consistency of the building geometric structure, an innovative solution was applied - the method of vector addition - to modify the linear values (tie distances) of the external face of the building walls. A separate research problem tackled in the article, although not yet fully solved, is the issue of coordinates of corners of a building obtained after the application of the method of vector addition.
\end{abstract}

Keywords: RTN and RTX GNSS, surveys of buildings, indirect methods of measurement, vector addition, measurement control network

\section{INTRODUCTION}

The use of indirect methods of measurement in RTN GNSS technology to determine the position of corners of building structures is undoubtedly an important attribute in the development of modern surveying technology in engineering measurements. The most commonly used indirect methods of measurement include: distance-distance intersection, a point on a straight line and intersection of straight lines. Based on the research studies conducted in (Krzyżek, 2014) it can be concluded that only the method of distance-distance intersection produces the best results in every respect - getting the most probable coordinates and small values of their mean errors, as well as consistent geometric structure (consistency of tie distances). The other two methods provide very diverse results, both with respect to their mutual relationships, as well as relative to the values adopted as reference parameters (e.g., tacheometric measurement results). The objective of this article is to present innovative solutions, to modernize indirect methods of measurement involving the use of such algorithms which, in the end, would result in the values having at least the same accuracy parameters as the method of distance-distance intersection. 
A need to seek innovative solutions aiming to use real-time surveying technology in difficult field conditions was presented by (Bakuła, 2013, Pelc-Mieczkowska, 2012 and Ge et al., 2006). Further following similar approaches of researchers, solutions to precisely determine the position of buildings are sought, which are structures difficult to access also for RTN GNSS real-time surveying.

Each surveyed building with the specified X, Y coordinates in the defined Cartesian coordinate system, must absolutely be verified by check measurements. The most commonly used check measurement for buildings includes the measurement of tie distances. There are no specific legal regulations which would define permissible differences in check measurements (tie distances) relative to the calculations obtained from the coordinates. Undoubtedly, however, the higher the value of these differences, the greater the uncertainty of the position of a building structure. In the case of a field detail of the first-order accuracy (a building), the certainty or uncertainty of its determination can not be subject to a discussion. Tie distances obtained from check measurements relative to the ones calculated from the coordinates should ensure full consistency of the geometric structure of the building in relation to reality. Therefore, while performing surveys of buildings in RTN GNSS mode using indirect methods of measurement, it is essential to aim at full consistency of the mentioned check measurements. Such consistency, however, is ensured only by one of the methods - distance-distance intersection (Krzyżek, 2014). Other methods include one of the most important factors which generates differences in tie distances, i.e. the setting out (fitting) error of a point (a corner of a building) to a given straight line (Beluch and Krzyżek, 2005). The setting out error is an element that can not be fully eliminated by using the existing, well known methods to minimize measurement errors. Therefore, a solution should be sought, which would ensure the consistency of tie distances not at the stage of the measurement results obtained in RTN GNSS surveying, but in the further process related to their study. It should be noted, however, that the stage of studying the RTN GNSS measurement results could, or even should be automated and implemented immediately after obtaining the results of a check measurement (tie distances) in the field.

Regardless of the technological solutions applied to determine the position of field details, any measurement results will always contain errors. In accordance with the law of error propagation, the more components generate the final result of the measurement, the greater the probability that the mean error of the determined object position will tend to increase. Different range of errors, their impact and minimizing the impact on the final results of the measurements were presented in (Kowalczyk, 2011). In the context of this article, the accuracy of the corner position is significantly affected by the mean error of determining base points (Fig. 1), based on which indirect methods of measurement are used (Krzyżek, 2014 and Kowalczyk, 2011). Due to the manner of using base points to determine corners of buildings, the base points can be, or actually should be, classified as the measurement control network. Accordingly, the method of establishing, surveying and performing the necessary check measurements of the base points in RTN GNSS mode should meet the requirements defined in (MIA, 2011).

Unfortunately, the Regulation (MIA, 2011) does not clearly specify the issue of applying a different innovative measurement technology in RTX (Real Time Extended) for the establishing and measuring of a control network, and thus of base points. Although it authorizes the use of the so-called other measurement techniques that meet the accuracy criteria of the Regulation (MIA, 2011), but the lack of clear regulations contributes frequently to different interpretations of this provision, discrediting a modern measurement technique already at the early stage. The principle of operation of RTX measurement technology with xFill function was presented in detail in (Leonardo et al., 2011). However, in (Krzyżek, 2013) 
attention was drawn to the possibilities of using this modern method of measurement for establishing measurement control networks. The use of RTX technology to determine the position of the measurement control network (base points), in the context of using indirect methods of measurement for the corners of buildings, should be resolved on an individual basis for each measurement. The final decision on the use of RTX technology should dependent on the awareness of the values of allowable base point position errors for certain indirect method of measurement. However, regardless of certain limitations which are inherent to the RTX technique, associated research allows for optimistic assumptions as to the applicability of the RTX technology and indirect methods of measurement to determine the position of buildings.

\section{ALGORITHM OF VECTOR ADDITION IN INDIRECT METHODS OF MEASUREMENT}

The differences between check measurements (tie distances) and calculated elements based on the $\mathrm{X}, \mathrm{Y}$ coordinates in the methods of intersection of straight lines or a point on a straight line range from several to tens of centimeters. In order to eliminate these differences, routing of the point (corner of a building) should be carried out, which is determined indirectly along the directions which are external faces of the walls of the building with a common vertex at the determined point. Such modernization of indirect methods of measurement, and more specifically, of the results obtained from the use of these methods in RTN GNSS surveying, should ensure the consistency of the geometric structure of the building relative to the actual dimensions. The method applied for routing the determined point is vector addition. The general principle of its implementation has been illustrated in Figure 1. This figure shows two independently used indirect methods of measurement: a point on a straight line and intersection of straight lines. 


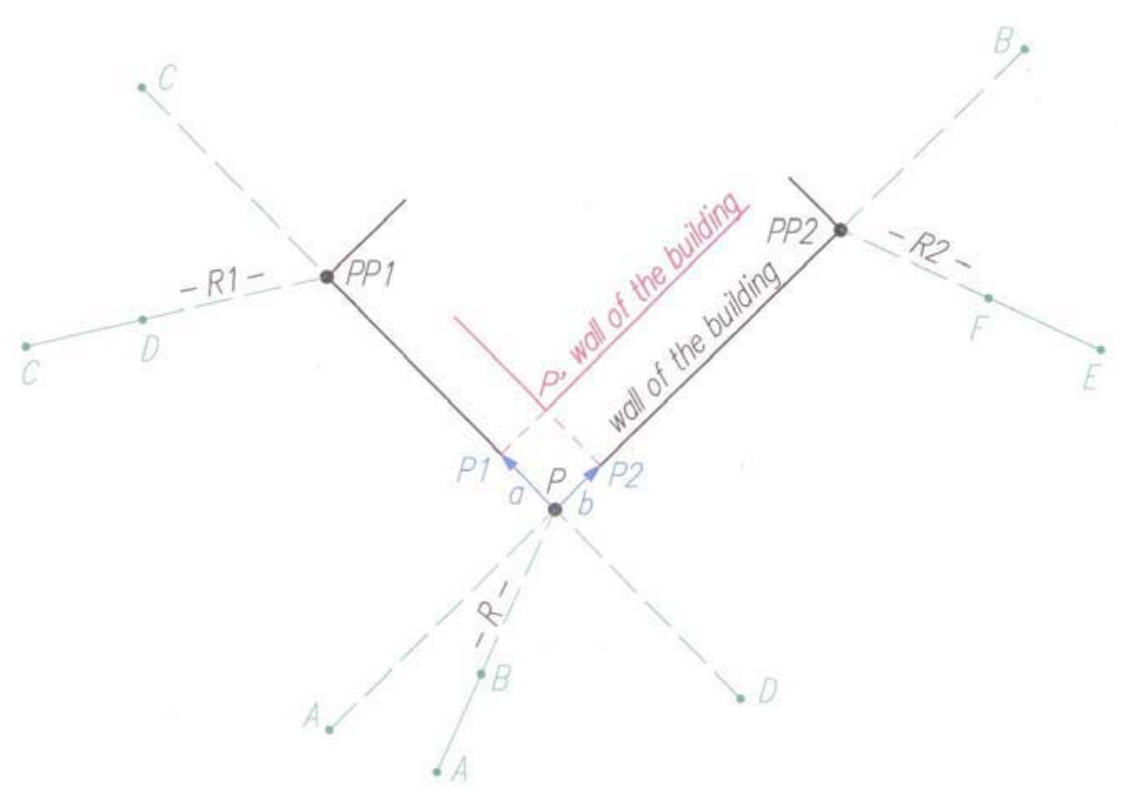

Legend:

A, B, C, D, E, F, ... - base points surveyed with RTN GNSS technology,

$\mathbf{R}_{\mathbf{i}}$ - linear measurement of the sections B-P, D-P, F-P, i_th-P with an open frame tape measure,

P, PP1, PP2 - a point (a corner of a building) determined indirectly,

$\mathbf{a}, \mathbf{b}$ - vectors determined based on differences in tie distances,

$\mathbf{P 1}, \mathbf{P 2}$ - auxiliary points determined based on the vectors $a$ and $b$,

P' - a point of the corner determined after the application of the method of vector addition.

Fig. 1. Application of vector addition to routing of the point determined in RTN GNSS mode using indirect methods of measurement - a point on a straight line and intersection of straight lines

The practical implementation of the method of vector addition to routing corners of buildings determined in RTN GNSS mode of surveying, using indirect methods of measurement - a point on a straight line and intersection of straight lines, is as follows:

1. Determining the position of the points $P_{i}$ of all the corners of a building in RTN GNSS mode of surveying, using indirect methods of measurement: a point on a straight line and intersection of straight lines, as well as calculating the coordinates from tie distances. In Figure 1, (in order to diversify and make easier the designations in the formulae for the method of a point on a straight line), adjacent points with respect to the exemplary point $P$ have been marked as $P P 1$ and $P P 2$.

2. Check measurement of the external face of the building walls (tie distances) with an open frame tape measure.

3. Calculating differences in tie distances with respect to individual walls of the building. At this stage, a very important factor is the appropriate sign (+ or -) of the obtained tie distance differences, and therefore the awareness which external faces of the building walls should be reduced, and which extended, relative to the actual dimensions. An error at this stage generates even greater errors regarding the position of the corners than the results obtained from the directly used measurement technology.

4. Calculating vectors $a$ and $b$ (Fig. 1) which are half of the values of the obtained tie distance differences for individual walls of the building.

5. Calculating coordinates $\mathrm{X}$ and $\mathrm{Y}$ of the points $P_{1}$ and $P_{2}$ for i-th walls of the buildings relative to the points $P_{i}$ determined in RTN GNSS, using: 
for the method of a point on a straight line

- $\mathrm{X}, \mathrm{Y}$ coordinates of the measurement station $P_{i}$, as well as polar coordinates, or the vectors $a$ and $b$, and azimuths $A_{P-P P 1}$ and $A_{P-P P 2}$, respectively.

for the method of intersection of straight lines

- $\mathrm{X}, \mathrm{Y}$ coordinates of the measurement station $P_{i}$, as well as polar coordinates, or the vectors $a$ and $b$, and azimuths $A_{P-C}$ and $A_{P-A}$, respectively.

The azimuth of the sides P-C or P-A can be replaced with the azimuth of the sides P-D or P-B respectively, depending on the sign ( + or - ) of the vectors $a$ and $b$.

6. Calculating the position of the point $P^{\prime}$ by applying the method of vector addition of the vectors $a$ and $b$ relative to the point $P$ - routing the position of the corner $P$ - with the formulae (1) and (2) (for editorial reasons, the formula presented below is for one of the indirect methods only, i.e. line-line intersection):

$$
\begin{aligned}
& X_{P^{\prime}}=\left(\frac{Y_{C}-Y_{A}+\operatorname{tg} A_{(A B)} \cdot X_{A}-\operatorname{tg} A_{(C D)} \cdot X_{C}}{\operatorname{tg} A_{(A B)}-\operatorname{tg} A_{(C D)}}+a \cdot \cos A_{(P-C)}\right) \\
& +\left(\frac{Y_{C}-Y_{A}+\operatorname{tg} A_{(A B)} \cdot X_{A}-\operatorname{tg} A_{(C D)} \cdot X_{C}}{\operatorname{tg} A_{(A B)}-\operatorname{tg} A_{(C D)}}+b \cdot \cos A_{(P-A)}\right) \\
& -\frac{Y_{C}-Y_{A}+\operatorname{tg} A_{(A B)} \cdot X_{A}-\operatorname{tg} A_{(C D)} \cdot X_{C}}{\operatorname{tg} A_{(A B)}-\operatorname{tg} A_{(C D)}} \\
& Y_{P^{\prime}}=\left[Y_{A}+\operatorname{tg} A_{(A B)} \cdot\left(\frac{Y_{C}-Y_{A}+\operatorname{tg} A_{(A B)} \cdot X_{A}-\operatorname{tg} A_{(C D)} \cdot X_{C}}{\operatorname{tg} A_{(A B)}-\operatorname{tg} A_{(C D)}}-X_{A}\right)+a \cdot \sin A_{(P-C)}\right] \\
& +\left[Y_{A}+\operatorname{tg} A_{(A B)} \cdot\left(\frac{Y_{C}-Y_{A}+\operatorname{tg} A_{(A B)} \cdot X_{A}-\operatorname{tg} A_{(C D)} \cdot X_{C}}{\operatorname{tg} A_{(A B)}-\operatorname{tg} A_{(C D)}}-X_{A}\right)+b \cdot \sin A_{(P-A)}-Y_{A}\right. \\
& \left.+\operatorname{tg} A_{(A B)} \cdot\left(\frac{Y_{C}-Y_{A}+\operatorname{tg} A_{(A B)} \cdot X_{A}-\operatorname{tg} A_{(C D)} \cdot X_{C}}{\operatorname{tg} A_{(A B)}-\operatorname{tg} A_{(C D)}}-X_{A}\right)\right]
\end{aligned}
$$

7. Re-analysis of tie distances obtained from the check measurement and calculated based on the coordinates of the points $P_{i}^{\prime}$ (corners of a building) having applied the method of vector addition. As a result of re-examination of tie distances, the consistency of the check measurements will not exceed the level of the adopted linear measurement error, depending on various factors, and therefore at the level of $\pm 0.01 \mathrm{~m}$ to $\pm 0.02 \mathrm{~m}$.

In this way, a new position of corners of a building will be determined - the points $P_{i}^{\prime}$ - for which the consistency of tie distances with respect to the check measurements will be implemented. This will ensure the consistency of the geometric structure of the building relative to the actual measurement results in the field. Applying the method of vector addition to route the corners of a building determined in RTN GNSS mode of surveying, however, is not equivalent to obtaining real, or most probable coordinates $\mathrm{X}$ and $\mathrm{Y}$ of these points.

\section{PRELIMINARY ASSESSMENT OF THE RELIABILITY OF DETERMINING CORNERS OF BUILDING STRUCTURES USING THE METHOD OF VECTOR ADDITION}

Due to the limited volume of the article, preliminary assessment of the reliability of determining corners of building structures will only be presented for the method of line-line intersection. In the performed analysis, a model of a building (Fig. 2) was adopted, for which some assumptions were made. The coordinate system was defined along the walls of the building and theoretical coordinate values of the corners of the building (in green) were assumed. The blue color marked the building which resulted from the use of the method of 
line-line intersection of the base points $(A-H)$ determined in the RTN GNSS mode. In order to ensure a better visualization of the relationships between the attributes of the method of vector addition, the areas of the corners of the building were enlarged (Fig. 2.1 - 2.4).

For the coordinates of the corners, after using the method of vector addition, to be more reliable than the coordinates of the same points obtained from raw results of line-line intersection, it must be proved equation (3):

$$
D_{N r-N r T}<D_{N r^{\prime}-N r T}
$$

where:

$D$ - the distance between two adjacent corners of the building,

$N r T$ - the number of the corner of the building of the theoretical position,

$N r^{\prime}$ - the number of the corner of the building resulting from the use of the method of line-line intersection,

$\mathrm{Nr}$ - the number (final) of the corner of the building resulting from the use of the method of vector addition

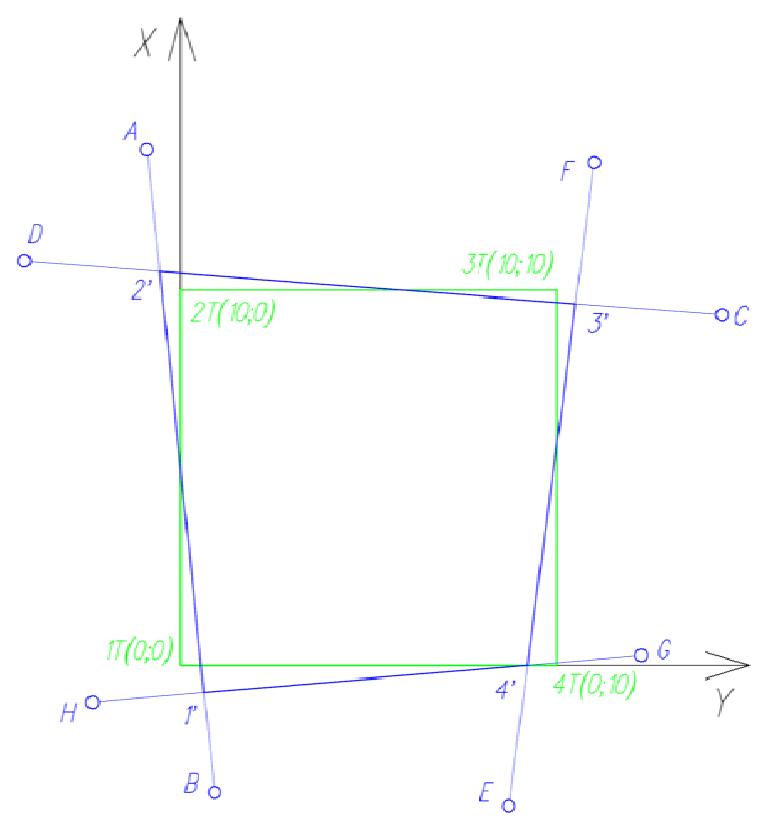

Fig. 2. Examples of the relationships between the corners of the building determined in the

\section{Legend:}

RTN GNSS mode, using the method of line-line intersection.

$A-H$ - base points determined in the RTN GNSS mode,

$1^{\prime}-4^{\prime}$ - corners of the building resulting from the use of the method of line-line intersection,

$1 T-4 T$ - theoretical position of the corners,

$a_{n}, b_{n}$ - vectors resulting from control measurement of tie distances of the building wall faces,

$d X^{\prime}, d Y^{\prime}$ - components of the $X, Y$ coordinates of the corners of the building from line-line intersection relative to the theoretical values.

- - fragment of the wall face of the building of the theoretical position,

- - fragment of the wall face of the building resulting from the use of the method of line-line intersection, vector addition

$\sum_{-}$- the length of the vectors $a$ and $b$ (point 4 of the algorithm of vector addition) 


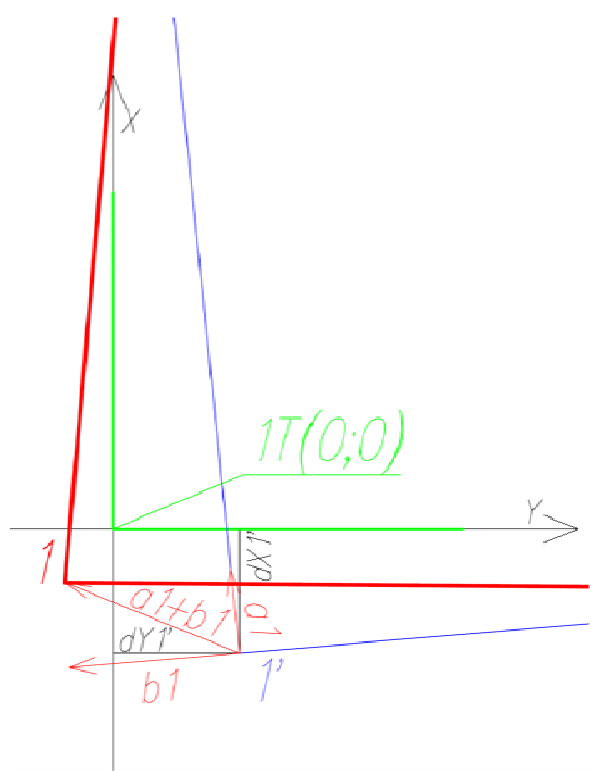

Fig. 2.1. Point no. 1

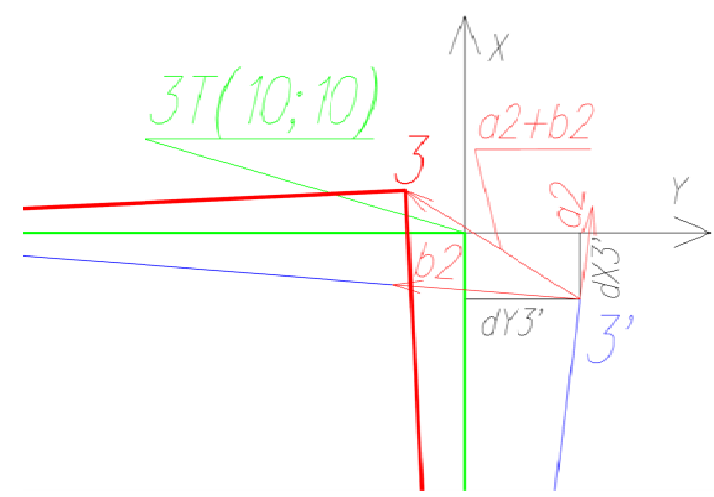

Fig. 2.3. Point no. 3

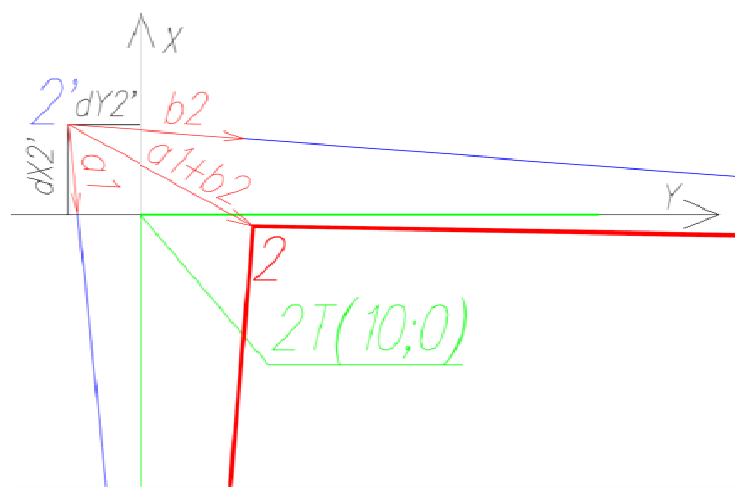

Fig. 2.2. Point no. 2

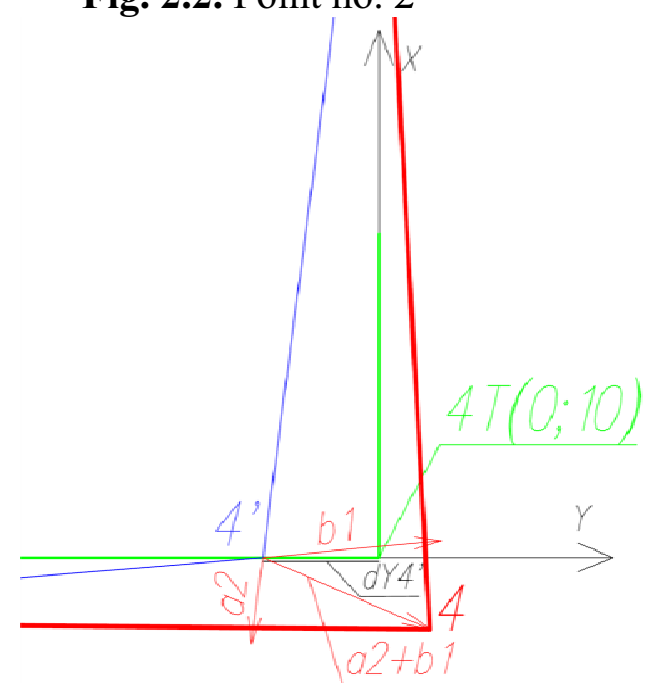

Fig. 2.4. Point no. 4

Having calculated the $X, Y$ coordinates of the terminal points of the vectors $a_{n}$ and $b_{n}$, the following formulae were obtained (4) and (5):

$$
\begin{aligned}
& X_{i}=X^{\prime}+a_{n} \cdot \cos A_{P_{i}-K_{i}}+b_{n} \cdot \cos A_{P_{j}-K_{j}} \\
& Y_{i}=Y^{\prime}+a_{n} \cdot \sin A_{P_{i}-K_{i}}+b_{n} \cdot \sin A_{P_{j}-K_{j}}
\end{aligned}
$$

Inaccuracy of setting out the corner of a building to the appropriate straight line along the $X$ and $Y$ axes was denoted by $d X_{N r^{\prime}}$ and $d Y_{N r^{\prime}}$, respectively. It results both from the setting-out errors regarding the corners, as well as from measurement of the base points in the RTN GNSS mode. To simplify the considerations, it was assumed that $d X_{N r^{\prime}}=d Y_{N r^{\prime}}$ (a different value for each corner), and finally it was denoted as $d X_{N r^{\prime}}$. Obviously, a situation which most often occurs in practice, is variability of inaccuracies of setting out a corner of a building in the direction of the coordinate axes, i.e. $d X_{N r^{\prime}} \neq d Y_{N r^{\prime}}$. In this case, one of those values is always smaller than the other one. The assumption $d X_{N r^{\prime}}=d Y_{N r^{\prime}}$ is to generate a potential 
situation in which vector addition (where $d X_{N r^{\prime}}=d Y_{N r^{\prime}}$ ) will always be greater than in the case where $d X_{N r^{\prime}} \neq d Y_{N r^{\prime}}$, while assuming the increase of the lower component value, for example $d X_{N r^{\prime}}$ to the larger component value $d Y_{N r^{\prime}}$ (or vice versa). Using this assumption, and introducing into the equation (3) additional denotations:

$r=a_{n} \cdot \cos A_{P_{i}-K_{i}}$

$w=b_{n} \cdot \cos A_{P_{j}-K_{j}}$

$s=a_{n} \cdot \sin A_{P_{i}-K_{i}}$

$q=b_{n} \cdot \sin A_{P_{j}-K_{j}}$

the formulae (6-9) for the points 1-4 were obtained (Fig. 2.1-2.4), which are a further development of the inequality (3):

- for the point 1

$$
2 d X_{1}(r+w+s+q)+r^{2}+w^{2}+s^{2}+q^{2}+2(r \cdot w+s \cdot q)<0
$$

- for the point 2

$$
2 d X_{1}(r+w-s-q)+r^{2}+w^{2}+s^{2}+q^{2}+2(r \cdot w+s \cdot q)<0
$$

- for the point 3

$$
2 d X_{1}(s+q-r-w)+r^{2}+w^{2}+s^{2}+q^{2}+2(r \cdot w+s \cdot q)<0
$$

- for the point 4

$$
2 d X_{1}(s+q-r-w)+r^{2}+w^{2}+s^{2}+q^{2}+2(r \cdot w+s \cdot q)<0
$$

For the formulae (6-9), an assessment of the formation of the value $d X_{N r}$ was performed (Table 1). This analysis considered two options of the relationships between the values of the vectors $a_{n}$ and $b_{n}$. The values of the azimuths $A_{P_{i}-K_{i}}, A_{P_{j}-K_{j}}$ had virtually no effect on the results, so eventually they were neglected as dependent variables relative to the other values, and deliberately distorted by 5 gon relative to the theoretical values in the direction illustrated in Figure 2.

Table. 1 Extremum of the values of $d X_{N r}$, for which the inequality (2) is satisfied

\begin{tabular}{|c|c|c|c|c|}
\cline { 2 - 5 } \multicolumn{1}{c|}{} & $\begin{array}{c}a_{1}=[0,005- \\
0,100]\end{array}$ & $b_{1}=2 a_{l}$ & $b_{2}=b_{I}$ & $a_{2}=a_{1}$ \\
\cline { 2 - 5 } \multicolumn{1}{c|}{} & \multicolumn{4}{c|}{$d X<\ldots$} \\
\hline$a_{1}[\mathrm{~m}]$ & point no. 1 & point no.2 & point no.3 & point no.4 \\
\hline 0.005 & 0.004 & 0.004 & 0.004 & 0.006 \\
\hline 0.010 & 0.009 & 0.009 & 0.008 & 0.011 \\
\hline 0.020 & 0.017 & 0.017 & 0.016 & 0.023 \\
\hline 0.040 & 0.034 & 0.035 & 0.033 & 0.046 \\
\hline 0.050 & 0.043 & 0.044 & 0.041 & 0.057 \\
\hline 0.060 & 0.052 & 0.052 & 0.049 & 0.069 \\
\hline 0.075 & 0.064 & 0.065 & 0.061 & 0.086 \\
\hline 0.100 & 0.086 & 0.087 & 0.081 & 0.114 \\
\hline
\end{tabular}


Adopting the parameter $a_{l}$ at the level between $0.005 \mathrm{~m}$ and $0.100 \mathrm{~m}$ is associated with the values which can often be obtained from control measurements of tie distances of a building surveyed in real time using the method of line-line intersection. The mutual relationships between the vectors $a_{n}, b_{n}$ (Tab. 1) allow to consider situations in which the differences in lengths of the building walls from the RTN GNSS measurement, relative to the actual values, fall in the range between $0.01 \mathrm{~m}$ and $0.40 \mathrm{~m}$. Although, most frequently, these are the values around $0.10 \mathrm{~m}$ or several centimeters, so widely accepted spectrum of discrepancies in control measurements will allow for even greater reliability of the presented conclusions drawn from the research study.

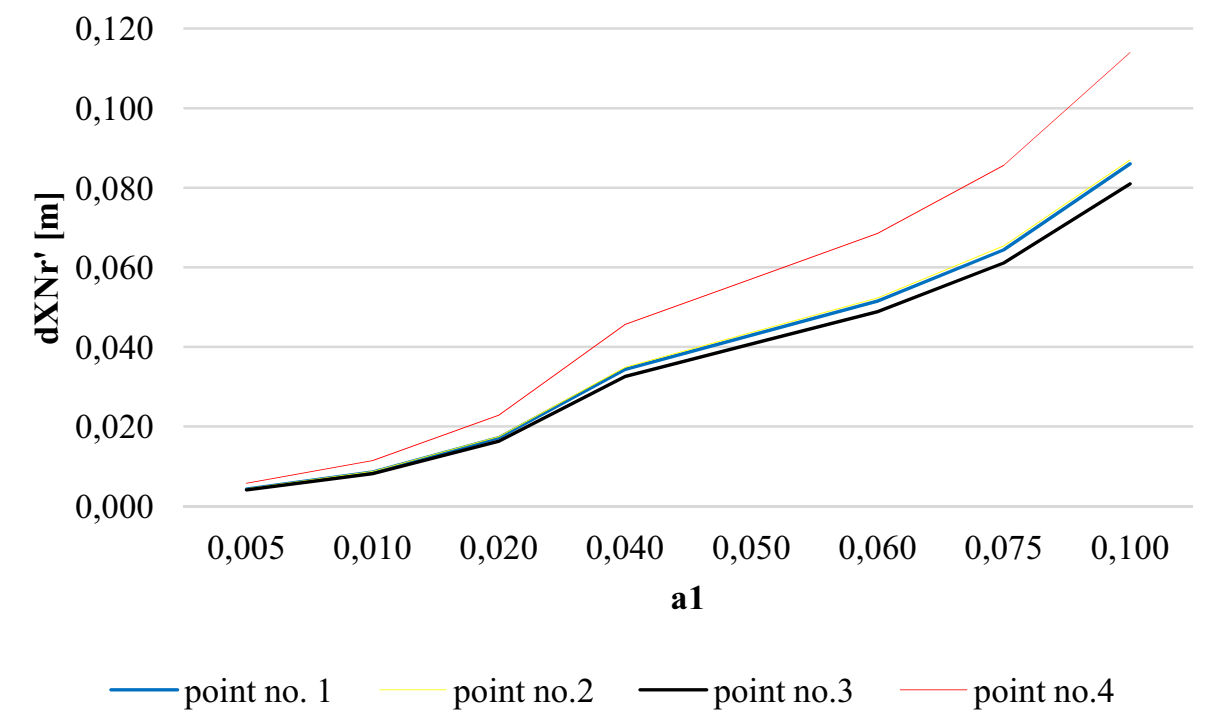

Fig. 3. Formation of the maximum values of $d X_{N r}$, for which the inequality (2) is satisfied

The results contained in Table 1 are illustrated in Fig. 3. Both Table 1 and Figure 3 clearly depict that the values of $d X_{4}$, are larger than those of other points $1^{\prime}-3^{\prime}$. This is due to the random location of the point $4^{\prime}$ on the line of the building wall, along the coordinate axes $Y$. Tab. 1 and Fig. 3 also present that for the points $1^{\prime}-3^{\prime}$ the values of $d X_{N r}$, are at a similar level to the corresponding values of the vectors $a_{1}$. The convergence of these results falls in the range between $85 \%$ (for $a_{1}=0.075 \mathrm{~m}$ ) and $100 \%$ (for $a_{1}=0.005 \mathrm{~m}$ ). This allows to draw preliminary conclusions that high accuracy of fitting the corner to the appropriate line of the wall of a building after using the method of vector addition has a significant effect on the reliability of the determined coordinates of the corners of a building. Small values resulting from the differences in control measurements of tie distances (up to $0.04 \mathrm{~m}$ ), i.e. $a_{1}$ up to $0.02 \mathrm{~m}$, are extremely difficult to achieve in practice. However, if this value is increased twice, or even three times (which are the most common cases), then an error may occur of up to about $0.05 \mathrm{~m}$, regarding fitting the corner to the appropriate line of the wall, relative to its actual position. Such an accuracy of setting out the corner of a building requires much experience from the surveyor, however, it definitely is achievable. The value of the parameter $d X_{N r}$, will largely be generated by the field conditions during the surveys, such as an open horizon for RTN GNSS measurements, a possibility of a close location of the base points relative to the corner of a building, and topography. In practice, these field attributes are strongly diversified. This, in turn, implies that the application of the method of vector addition for the corners of buildings determined in the RTN GNSS mode, may improve the reliability of the modified coordinates only for a certain group of points (corners of a building). 


\section{RESEARCH METHODS AND RESEARCH EXPERIMENT}

In order to confirm the results of the applied research methods, experiments on the test structures (single-family houses) were carried out, including a total of 56 points being determined (corners of buildings), located in two municipalities: Jerzmanowice-Przeginia in Krakow district (20 points) and Węgierska Górka in Żywiec district (36 points). Due to the limited volume of the article, only the analysis of the results of the research experiment for the object located in the municipality of Jerzmanowice-Przeginia has been presented (Fig. 4). For the second test structure (Węgierska Górka), a detailed description of the research studies, their results and the assessment of the accuracy have been presented in (Krzyżek, 2015), where other innovative solutions were also examined. In (Krzyżek, 2015), in addition to the author's own solutions, the method of vector addition was used again as well, in the context of the mutual relationships of tie distances, in order to present the scale of mutual differences between the analyzed methods. However, for editorial reasons, the mutual relationships in the coordinate differences after applying the method of vector addition, have not been not presented, although they were subject to the research, too. Nevertheless, the conclusions of these studies (both in relation to the tie distances and the coordinate differences) are consistent with the results of the research experiment, presented in this article.

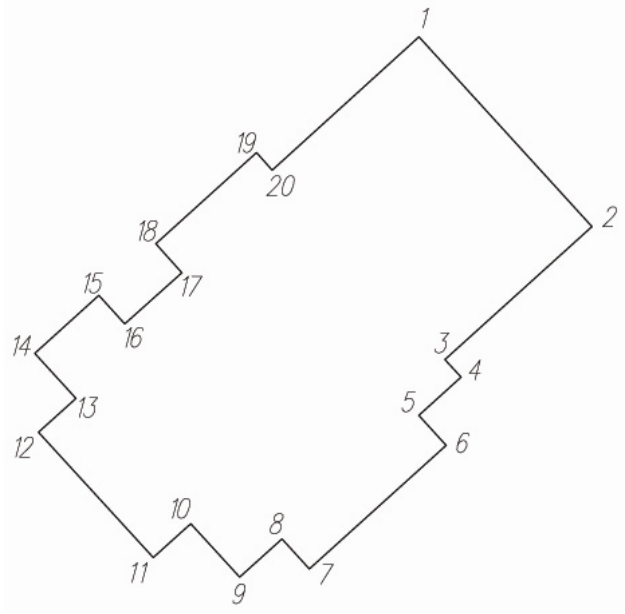

Fig. 4. Single-family house - the test object

A description of the whole conducted experiment was presented in (Krzyżek, 2014). In order to remind the basic field activities in the context of the analyzed research studies in this article, a description of the experiment was included. All the corners 1-20 of the building (Fig. 4) were surveyed with RTN GNSS technology using three indirect methods of measurement: a point on a straight line, intersection of straight lines and distance-distance intersection. During the implementation of the method of a point on a straight line, a very important factor was the use of an open frame tape measure as the linear measurement, arranged along the line of: the base points - the corner of the building, which definitely contributed to the minimization of setting-out errors. During the surveys with the method of intersection of straight lines, the position of the two points (16 and 17) was determined by the intersection of the straight lines: external face of the building walls (15-16 and 18-17, respectively) with a straight line from any available direction for the given corner of the building. The surveys were performed in real time, using the Topcon HiperPro receiver, in relation to the reference station network MSPP (Malopolska Precision Positioning System), which are also stations of the national positioning system ASG EUPOS. The main advantage of MSPP is the use of two satellite systems: GPS and GLONASS.

The ASG EUPOS system, which has been operating in Poland since 2008, is still subject to various modifications and improvements. Research studies are being conducted in order to 
increase the efficiency and accuracy of GNSS measurement results using reference station network system (Figurski et al., 2011), and even the implementation of satellite measurements outside the ASG EUPOS network (Paziewski et al., 2014). Regardless of whether the ASG EUPOS station network is used in the kinematic or static mode of measurements, almost all scientists involved in the study of the GNSS satellite systems agree on a need to use not only GPS, but also GLONASS, and in the near future also GALILEO systems in satellite measurements. The benefits of using a multi-constellation system were presented in the studies of (Angrisano et al., 2013), emphasizing greater accuracy, continuity and integrity of positioning. Similar advantages of using multiple satellite systems in real-time measurements were presented in (Pirti et al., 2013), who, in various satellite constellations, examine the efficiency and precision of the results obtained in the field, with the horizon both visible and obscured by the trees. Also (Teng et al., 2015), while analyzing the effect of the accuracy of the geometry of multiple satellite systems on the precision of the determined position, present a closed formula to calculate the geometric dilution of precision (GDOP) for the multiconstellation system, which definitely simplifies and accelerates the determination of this coefficient. On the other hand, (Zhang and $\mathrm{Li}, 2013$ ) focus the results of their research studies performed with the use of GPS and GLONASS systems in the context of obtaining a convergent solution reduced by up to $42 \%$, as compared to the measurements based solely on GPS.

As a result of the survey of the test structure (a building), for each indirect method $\mathrm{X}, \mathrm{Y}$ coordinates in the PL-2000 system were obtained (average value of 30 epochs). Then, for the research purposes, a measurement control was established on the structure, whose $\mathrm{X}, \mathrm{Y}$ coordinates were determined in the PL-2000 system with GNSS surveys with the static method, in relation to the reference station network MSPP. The time of each measurement session lasted 110 minutes. Using POZGEOD service of ASG EUPOS, the coordinates of the measurement control points were adjusted, to obtain a mean position error $m_{P}$ of the points at the level of a few millimeters. The control was a reference for surveying buildings with the tacheometric method. High accuracy of determining the position of the control points allowed to adopt the tacheometric measurement results as a benchmark for the $\mathrm{X}$ and $\mathrm{Y}$ coordinates obtained from the RTN GNSS surveying. In this way, a homogeneous character of the measurement control coordinates and the corners of the building determined in real time and with the tacheometric method was obtained. For all the test points of the building, check measurements were performed in the form of tie distances. Two out of the three indirect methods were subject to further tests, namely the method of intersection of straight lines and a point on a straight line. The validity of this assumption was confirmed by the studies carried out in (Krzyżek, 2014).

In order to analyze the results which were obtained from the tacheometric surveys of the building and RTN GNSS technology using two indirect methods of measurement and taking into account the method of vector addition, relevant comparisons of the results obtained from each measurement method were made. First, the differences in tie distances between check measurements and the values calculated from the coordinates of the points of the corners, having used the method of vector addition, were analyzed (Table 2). The vector addition was applied only to the methods of intersection of straight lines and a point on a straight line. It (the method of vector addition) was not taken into account in the tacheometric method because tacheometry is not the subject of this study, and besides, it is a commonly used surveying technology which does not require any modernization. For the purpose of editing tables and figures, provisional designation of each method was made as follows: 
- tacheometric method - $T$,

- a point on a straight line - NP,

- intersection of straight lines $-P P$,

- open frame tape measurement $-R$.

Table. 2. Differences in tie distances dR comparing individual measurement methods

\begin{tabular}{|c|c|c|c|c|c|c|}
\hline Side & $T-P P[\mathrm{~m}]$ & $T-N P[\mathrm{~m}]$ & $T-R[\mathrm{~m}]$ & $P P-N P[\mathrm{~m}]$ & $P P-R[\mathrm{~m}]$ & $N P-R[\mathrm{~m}]$ \\
\hline $1 \_2$ & 0.010 & 0.010 & 0.010 & 0.000 & 0.000 & 0.000 \\
\hline $2 \_3$ & 0.005 & 0.003 & 0.004 & -0.002 & -0.002 & 0.001 \\
\hline 3_4 & -0.003 & -0.004 & -0.003 & 0.000 & 0.001 & 0.001 \\
\hline 4_5 & -0.004 & -0.002 & -0.003 & 0.003 & 0.002 & -0.001 \\
\hline 5_6 & -0.007 & -0.004 & -0.005 & 0.003 & 0.002 & -0.001 \\
\hline $6 \_7$ & -0.005 & -0.007 & -0.007 & -0.002 & -0.002 & 0.000 \\
\hline 7_8 & 0.015 & 0.003 & 0.004 & -0.012 & -0.011 & 0.001 \\
\hline $8 \_9$ & -0.006 & -0.007 & -0.007 & -0.001 & -0.001 & 0.000 \\
\hline 9_10 & -0.018 & -0.014 & -0.014 & 0.004 & 0.004 & 0.000 \\
\hline $10 \_11$ & 0.009 & 0.007 & 0.007 & -0.002 & -0.002 & 0.000 \\
\hline $11 \_12$ & -0.024 & -0.023 & -0.023 & 0.001 & 0.001 & 0.000 \\
\hline $12 \_13$ & 0.007 & 0.009 & 0.010 & 0.003 & 0.003 & 0.001 \\
\hline $13 \_14$ & -0.002 & -0.002 & -0.002 & 0.000 & 0.000 & 0.000 \\
\hline $14 \_15$ & -0.002 & -0.005 & -0.006 & -0.003 & -0.004 & -0.001 \\
\hline $15 \_16$ & -0.016 & -0.012 & -0.012 & 0.004 & 0.004 & 0.000 \\
\hline $16 \_17$ & 0.005 & 0.014 & 0.013 & 0.009 & 0.008 & 0.000 \\
\hline $17 \_18$ & -0.007 & -0.007 & -0.010 & 0.000 & -0.003 & -0.003 \\
\hline $18 \_19$ & 0.014 & 0.016 & 0.016 & 0.001 & 0.002 & 0.001 \\
\hline $19 \_20$ & 0.000 & -0.003 & -0.001 & -0.003 & -0.001 & 0.001 \\
\hline $20 \_1$ & -0.026 & -0.027 & -0.027 & -0.001 & -0.001 & 0.000 \\
\hline $\begin{array}{c}\text { Average } \\
\text { value of } \mu\end{array}$ & -0.003 & -0.003 & -0.003 & 0.000 & 0.000 & 0.000 \\
\hline $\begin{array}{c}\text { Mean } \\
\text { standard } \\
\text { deviation } \hat{\delta}\end{array}$ & 0.003 & 0.003 & 0.003 & 0.001 & 0.001 & 0.000 \\
\hline T-test model & -16.399 & -17.062 & -16.865 & -44.957 & -46.769 & -185.871 \\
\hline $\begin{array}{c}\text { For signifi- } \\
\text { cance level } \\
5 \% . \text { quantile } \\
k=n-1\end{array}$ & \multicolumn{6}{|c|}{19} \\
\hline $\begin{array}{c}\text { Critical } \\
\text { value of } \\
\text { Student's } t \text { - } \\
\text { distribution }\end{array}$ & \multicolumn{6}{|c|}{2.0930} \\
\hline $\begin{array}{l}\text { Choice of } \\
\text { hypothesis }\end{array}$ & $H(1)$ & $H(1)$ & $H(1)$ & $H(1)$ & $H(1)$ & $H(1)$ \\
\hline
\end{tabular}

Graphical presentation of the data contained in Table 2 has been illustrated in Figure 5. 


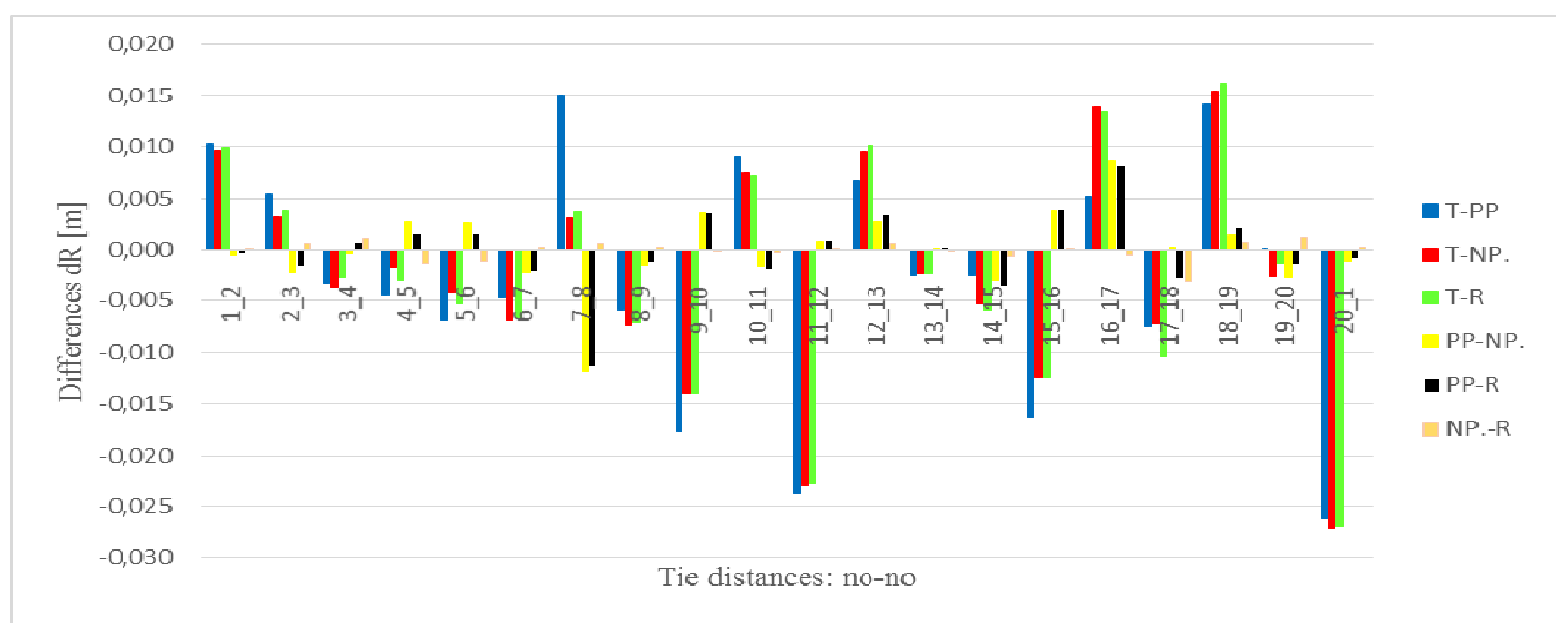

Fig. 5. Differences in tie distances $d R$ comparing individual measurement methods

Another analysis associated with the results obtained after applying the method of vector addition as compared to the data obtained from real-time measurements has been presented in Table 3. It refers to the differences between the coordinates $\mathrm{dX}$ and $\mathrm{dY}$ of the point $P^{\prime}$ after routing the position of the corner $P$ surveyed in the RTN GNSS mode.

Table. 3. Differences in coordinates $\mathrm{dX}, \mathrm{dY}$ and vector $\mathrm{dL}$ comparing individual measurement methods

\begin{tabular}{|c|c|c|c|c|c|c|c|c|c|}
\hline \multirow{2}{*}{ No. } & \multicolumn{3}{|c|}{$T-P P[\mathrm{~m}]$} & \multicolumn{3}{|c|}{$T-N P[\mathrm{~m}]$} & \multicolumn{3}{|c|}{$P P-N P[\mathrm{~m}]$} \\
\hline & $\mathrm{dX}$ & $\mathrm{dY}$ & $\mathrm{dL}$ & $\mathrm{dX}$ & $d Y$ & $\mathrm{dL}$ & $\mathrm{dX}$ & $d Y$ & $\mathrm{dL}$ \\
\hline 1 & 0.003 & -0.113 & 0.114 & 0.001 & 0.005 & 0.005 & -0.002 & 0.118 & 0.119 \\
\hline 2 & 0.012 & -0.089 & 0.090 & 0.006 & 0.025 & 0.026 & -0.006 & 0.114 & 0.114 \\
\hline 3 & 0.037 & -0.119 & 0.125 & 0.010 & 0.017 & 0.020 & -0.027 & 0.136 & 0.139 \\
\hline 4 & 0.018 & -0.144 & 0.145 & 0.003 & 0.004 & 0.005 & -0.015 & 0.148 & 0.149 \\
\hline 5 & -0.050 & -0.079 & 0.094 & -0.005 & 0.014 & 0.015 & 0.045 & 0.093 & 0.103 \\
\hline 6 & -0.017 & -0.052 & 0.054 & 0.000 & 0.013 & 0.013 & 0.017 & 0.065 & 0.067 \\
\hline 7 & 0.013 & -0.073 & 0.074 & 0.019 & 0.005 & 0.020 & 0.006 & 0.078 & 0.078 \\
\hline 8 & 0.007 & -0.102 & 0.102 & 0.022 & 0.004 & 0.022 & 0.015 & 0.106 & 0.107 \\
\hline 9 & -0.043 & -0.051 & 0.067 & 0.040 & -0.003 & 0.040 & 0.083 & 0.048 & 0.096 \\
\hline 10 & -0.011 & 0.009 & 0.014 & 0.021 & -0.003 & 0.021 & 0.032 & -0.012 & 0.034 \\
\hline 11 & 0.036 & -0.048 & 0.060 & -0.002 & 0.008 & 0.008 & -0.038 & 0.056 & 0.068 \\
\hline 12 & 0.013 & -0.038 & 0.040 & -0.023 & 0.019 & 0.030 & -0.036 & 0.057 & 0.067 \\
\hline 13 & -0.021 & 0.003 & 0.021 & 0.010 & 0.002 & 0.010 & 0.031 & -0.001 & 0.031 \\
\hline 14 & -0.026 & 0.001 & 0.026 & -0.002 & -0.008 & 0.008 & 0.024 & -0.009 & 0.026 \\
\hline 15 & 0.013 & -0.037 & 0.039 & 0.001 & -0.018 & 0.018 & -0.012 & 0.019 & 0.022 \\
\hline 16 & -0.043 & -0.116 & 0.124 & 0.003 & -0.033 & 0.033 & 0.046 & 0.083 & 0.095 \\
\hline 17 & -0.021 & -0.128 & 0.130 & -0.001 & -0.010 & 0.010 & 0.020 & 0.118 & 0.120 \\
\hline 18 & -0.008 & -0.103 & 0.103 & -0.007 & -0.005 & 0.009 & 0.001 & 0.097 & 0.097 \\
\hline 19 & -0.043 & -0.051 & 0.067 & 0.020 & -0.009 & 0.022 & 0.063 & 0.042 & 0.076 \\
\hline 20 & -0.036 & -0.043 & 0.056 & 0.038 & 0.008 & 0.039 & 0.074 & 0.051 & 0.090 \\
\hline Average value of $\mu$ & & & 0.077 & & & 0.019 & & & 0.085 \\
\hline $\begin{array}{c}\text { Mean standard } \\
\text { deviation } \hat{\delta}\end{array}$ & & & 0.009 & & & 0.002 & & & 0.008 \\
\hline T-test model & & & -2.614 & & & -34.134 & & & -1.853 \\
\hline $\begin{array}{c}\text { For significance level } \\
5 \% . \text { quantile } k=n-1\end{array}$ & & & & & 19 & & & & \\
\hline $\begin{array}{l}\text { Critical value of } \\
\text { Student's } t- \\
\text { distribution }\end{array}$ & & & & & 2.0930 & & & & \\
\hline Choice of hypothesis & & & $H(1)$ & & & $H(1)$ & & & $H(0)$ \\
\hline
\end{tabular}


In order to better illustrate the data contained in the Table 3, the formation of coordinate differences - vector $\mathrm{dL}$ - has been presented in Figure 6.

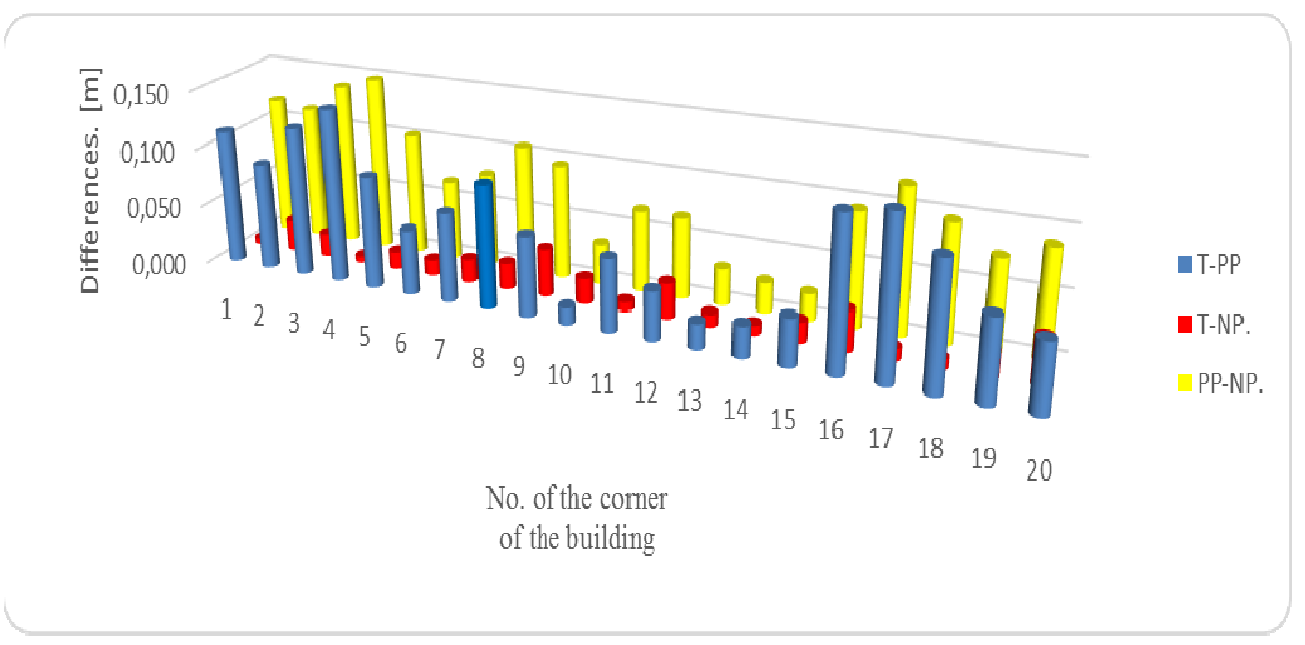

Fig. 6. Differences in coordinates - vector $\mathrm{dL}$ - comparing individual measurement methods

The data contained in Tab. 2-3 and Figures 5-6 were a test sample which was subjected to statistical analysis.

Statistical analysis carried out for the differences between the coordinates $d X$ and $d Y$ concerned exclusively their vector dL. Thus, Figure 6 is a graphical representation of the formation of vector $\mathrm{dL}$ only. Therefore, for the results contained in Tab. 2-3, and so, for the differences of the obtained tie distances $d R$ and vector $d L$ (having applied the method of vector addition), the null hypothesis $H_{0}$ was defined: the average value of $\mu$, for the differences in tie distances $d R$ in various combinations of the methods - T-PP, T-NP, T-R, PP$N P, P P-R, N P-R$ - and for the vectors $d L$ in various combinations of the methods T-PP, T-NP, $P P-N P$ - is equal to a fixed value of $\mu=0.10 \mu$ (formula 10)

$$
H_{0}: \mu=\mu_{0}
$$

For the null hypothesis, alternative hypothesis $H_{1}$ was defined: the average value of $\mu$, for the differences in tie distances $d R$ in various combinations of the methods - T-PP, T-NP, T-R, PP$N P, P P-R, N P-R$ - and for the vectors $d L$ in various combinations of the methods T-PP, T-NP, $P P-N P$ - is less than the predetermined value of $\mu_{0}$ (formula 11)

$$
H_{0}: \mu \leq \mu_{0}
$$

The explanation regarding the adopted fixed value of $\mu_{0}=0.10 \mathrm{~m}$ has been presented in (Krzyżek, 2014). The main assumption was to prove alternative hypotheses for the analyzed values: differences in tie distances $\mathrm{dR}$ and vectors $\mathrm{dL}$. Therefore, the mean value of $\mu$ with respect to each relationship in individual methods was calculated in the first place. The next step was to calculate the mean value of the standard deviation $\delta$ from the following formula (12):

$$
\delta(\mu)=\frac{\hat{\delta}}{\sqrt{n}}
$$


where:

$\hat{\delta}$ - standard deviation for the tie distances $\mathrm{dR}$ and vectors $\mathrm{dL}$ in the various combinations of the calculation methods,

$\mathrm{n}$ - number of the differences in tie distances $\mathrm{dR}$ and vectors $\mathrm{dL}$ in the various combinations of the calculation methods.

To verify the defined hypotheses, one of the models of the $T$-test of a single mean value was specified (formula 13). The choice of such a $T$-test model was based on the test sample number $(<30)$.

$$
T=\frac{\mu-\mu_{0}}{\delta(\mu)}
$$

For the purposes of statistical analysis, a significance level $\alpha=5 \%$ and $k=n-1$ degrees of freedom were adopted, for which the variable of the $T$-test of a single mean value takes the Student's t-distribution. Further, for such parameters, two-tailed critical region was constructed including the quantile $t(\alpha, k)$.

Interpretation of the measurement results (Tab. 2 and Tab. 3) varies depending on the analyzed attributes (tie distances and coordinate differences). The method of vector addition used for routing corners of buildings determined in the RTN GNSS mode produces very good final results in terms of geometric conformity of the building in relation to the actual dimensions. Based on the statistical analysis (Tab. 2), with respect to all the relationships of individual methods, an unambiguous conclusion can be drawn: the average value of $\mu$, for the differences in tie distances $d R$ in various combinations of the methods - T-PP, T-NP, T-R, PP$N P, P P-R, N P-R$ - is statistically significant, resulting in the rejection of the hypothesis $H_{0}$ in favor of the hypothesis $H_{l}$. The results contained in (Tab. 2) and (Figure 5) unambiguously present the development of the differences in the building tie distances after the application of the method of vector addition to the methods of a point on a straight line and intersection of straight lines. The mean values of the obtained differences in tie distances are at the level of zero with negligible intervals of their formation: for the $P P$ method from $-0.011 \mathrm{~m}$ to $+0.008 \mathrm{~m}$, and for the $N P$ method from $-0.003 \mathrm{~m}$ to $+0.001 \mathrm{~m}$. The only exceptions to those values relate to the tacheometric method $(T)$ in indirect methods of measurement $(P P$ and $N P)$. Although in these cases the average values from the obtained differences in tie distances are also almost zero $(-0.003 \mathrm{~m})$, but with slightly larger ranges of their formation: for all methods from $-0.025 \mathrm{~m}$ to $+0.015 \mathrm{~m}$. However, in the context of detailed topographic surveys, the differences in the values of tie distances in the relationships of indirect methods of measurement with tacheometry are at a satisfactory level of accuracy. Using indirect methods of measurement ( $P P$ and NP) in RTN GNSS surveys to determine corners of a building, one of the greatest accuracy problems is fitting the point (the corner of a building) to the appropriate straight line. Therefore, it seems that the application of the method of vector addition in the indirect methods of measurement $P P$ and $N P$ ensures equidistant projection of a field object (a building) on the map.

The Regulation (MIA, 2011), which should clearly regulate all the matters related to detailed measurements, does not specify either any formulae or specific values, on the basis of which it would be possible to recognize or reject the resulting differences in check measurements of tie distances. However, since the differences between these tie distances after applying the method of vector addition are at the level of single millimeters, it can be concluded that the results of the measurements obtained using innovative solutions meet all the accuracy requirements (even if they are not set out in the legal acts). 
The usefulness of the method of vector addition in its application in order to obtain the most probable coordinates of corners of buildings is yet another issue. Here, the applied method does not seem to be effective. In this case, the $\mathrm{X}, \mathrm{Y}$ coordinates of reference for the coordinates of the methods $P P$ and $N P$ were the values obtained by the $T$ method. The validity of this assumption was presented in (Krzyżek, 2014). The conducted statistical analysis (Tab. 2 ), for the relationship of the methods $T-P P$ and $T-N P$, points to some conclusions which are similar to the ones for tie distances, which means that the average value of $\mu$, for the vectors $d L$ in various combinations of the methods - T-PP, T-NP - is statistically significant, resulting in the rejection of the hypothesis $H_{0}$ in favor of the hypothesis $H_{1}$. Only for the combination of the methods $P P-N P$, the conclusion from the conducted statistical analysis is different, namely that the average value of $\mu$, for the vectors $d L$ in PP-NP combination of the methods is statistically insignificant, resulting in a lack of evidence to reject the hypothesis $H_{0}$ in favor of the hypothesis $H_{1}$. Therefore, seemingly for the relationship of the methods T-PP and T-NP the method of vector addition also fulfills its functions. However, in order to draw definitive conclusions from the conducted study, it is still necessary to examine in detail the formation of coordinate differences $\mathrm{dX}$ and $\mathrm{dY}$ and vector $\mathrm{dL}$ in combinations of individual methods. In order to visualize the formation of the above-mentioned differences in the respective intervals, Figures 7-9 present frequency histograms of the measured values $\mathrm{dX}, \mathrm{dY}$, and $\mathrm{dL}$.

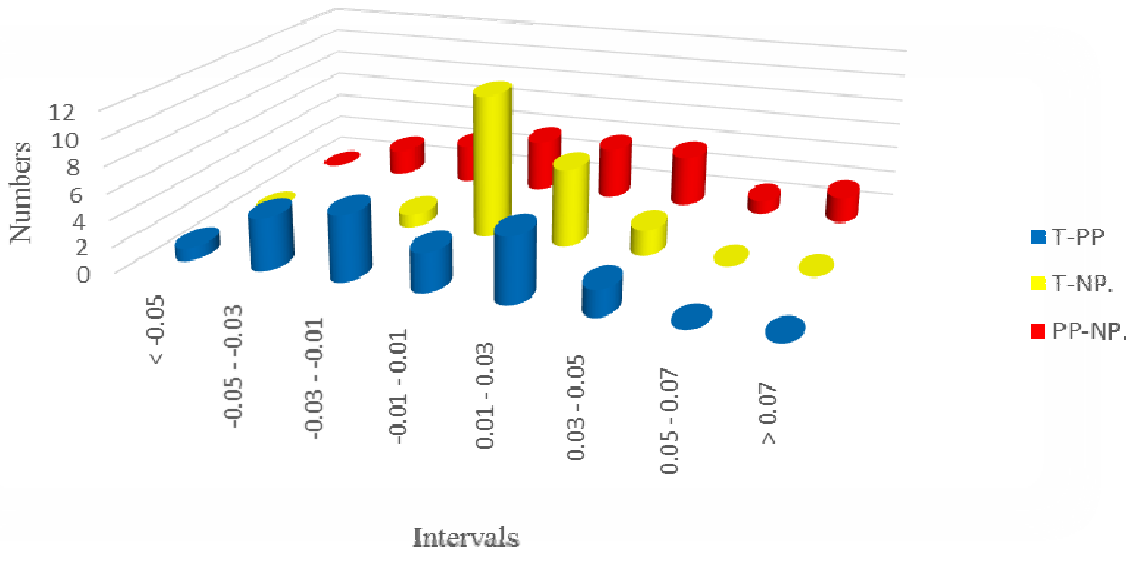

Fig. 7. Frequency histogram of the coordinate differences $d X$ at the corners of the building in the relationships of individual methods for specific intervals.

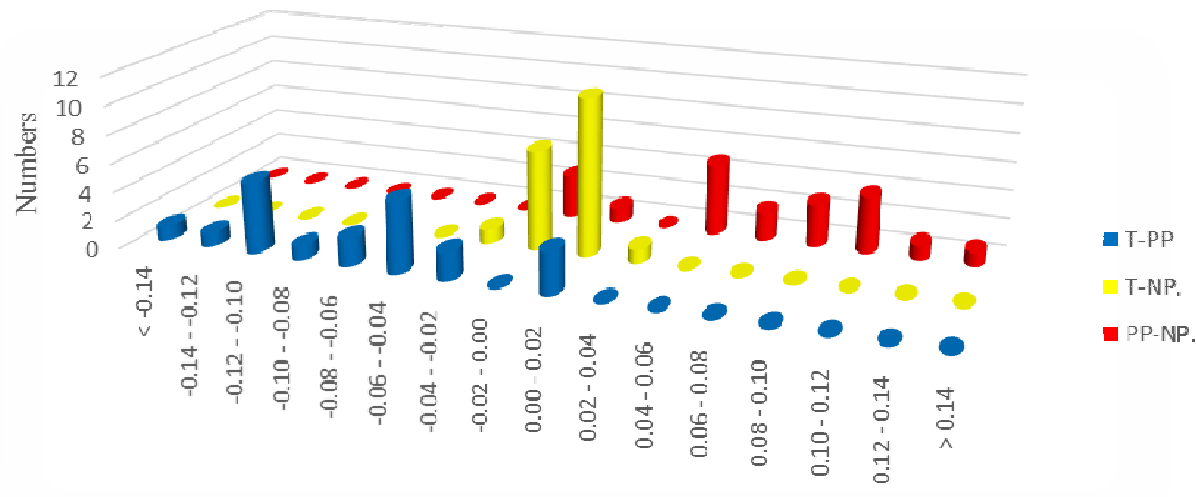

Intervals

Fig. 8. Frequency histogram of the coordinate differences $d Y$ at the corners of the building in the relationships of individual methods for specific intervals. 


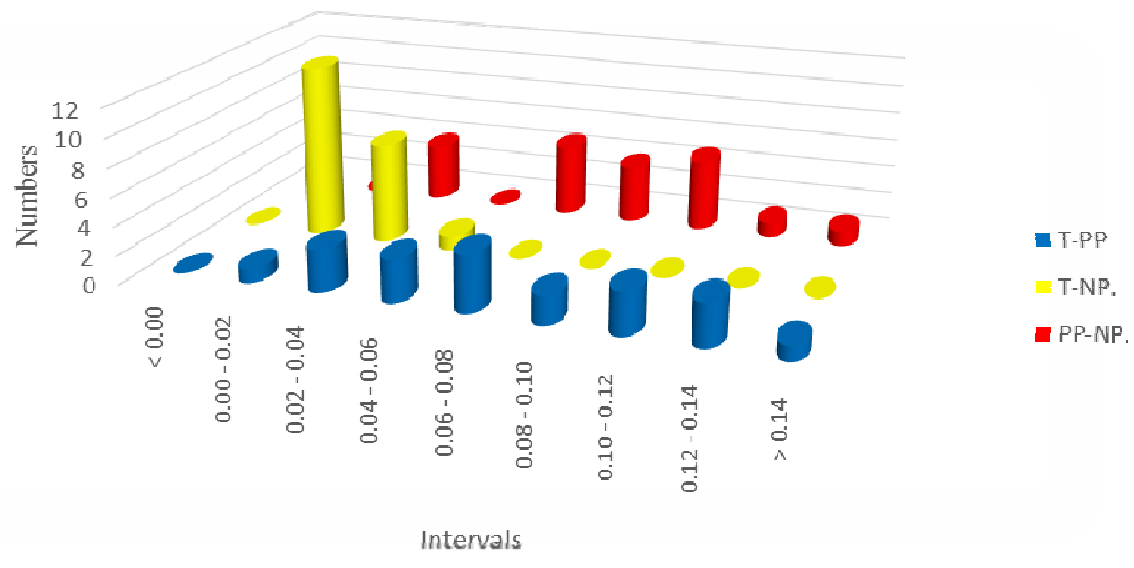

Fig. 9. Frequency histogram of the vector $\mathrm{dL}$ at the corners of the building in the relationships of individual methods for specific intervals.

For the relationship of the methods $T-P P$, the average values of the coordinate differences are: $\mathrm{dX}=-0.008 \mathrm{~m}, \mathrm{dY}=-0.069 \mathrm{~m}$ and vector $\mathrm{dL}=0.077 \mathrm{~m}$, in the intervals from $-0.050 \mathrm{~m}$ to + $0.037 \mathrm{~m}(\mathrm{dX})$, from $-0.144 \mathrm{~m}$ to $+0.009 \mathrm{~m}(\mathrm{dY})$, from $-0.014 \mathrm{~m}$ to $0.145 \mathrm{~m}(\mathrm{dL})$, respectively. Only the average values for the coordinate differences $\mathrm{dX}$ are at a satisfactory level of accuracy, although, when we take a look at their range, it is evident that it is approaching the boundary value of the mean position error of a detail of the first-order accuracy. The other analyzed elements ( $\mathrm{dY}$ and $\mathrm{dL}$ ) with average values significantly deviating from the value of $\mathrm{dX}$, also fit into very large intervals, of over a dozen centimeters. Such coordinate values, significantly different from the reference parameters ( $\mathrm{X}, \mathrm{Y}$ from tacheometry), can not be taken into account to be qualified as the most probable coordinates. Considering the relationship of the test model $T$ to the critical value of the Student's t-distribution, there is a small difference in these values, which ultimately translates into the conclusions drawn from the statistical analysis. If, however, the significance level $\alpha=10 \%$ was adopted, it would lead to the conclusion that there are no grounds to reject the hypothesis $\mathrm{H}_{0}$ in favor of the hypothesis $\mathrm{H}_{1}$. This exactly is the conclusion drawn from the statistical analysis for the relationship of the methods $P P-N P$. It results from a compilation of these methods with a predominance of low accuracy of the method $P P$. However, very interesting conclusions are drawn both from the statistical analysis (the conclusion mentioned above) of the compilation of the methods $T-N P$, as well as from the mutual formation of their coordinate differences $\mathrm{dX}$, $\mathrm{dY}$ and vector $\mathrm{dL}$. When we consider the range of the intervals of the coordinate values $\mathrm{dX}$, $\mathrm{dY}$ and vector $\mathrm{dL}$ having applied the method of vector addition, and we compare it with the research study conducted in (Krzyżek, 2014), we can see a significant reduction in the calculated differences dY and dL. For dY parameters, these differences decrease by $43 \%$ (they fall within the range of $-0.033 \mathrm{~m}$ to $0.025 \mathrm{~m}$ ), and for the vector dL by $36 \%$ (they fall within the range of $0.005 \mathrm{~m}$ to $0.040 \mathrm{~m}$ ). Only differences of $\mathrm{dX}$ coordinates increased slightly and now they fall within the range of $-0.023 \mathrm{~m}$ to $+0.040 \mathrm{~m}$. It should be noted, however, that the smallest value " $-0.023 \mathrm{~m}$ " refers to one point only, and the others are at the level of millimeters. When we take a look at the average values of the calculated coordinate differences again, we can notice that they are at a low level, and are as follows: $+0.008 \mathrm{~m}$ for $\mathrm{dX},+0.002 \mathrm{~m}$ for $\mathrm{dY}$, and $0.019 \mathrm{~m}$ for $\mathrm{dL}$. Thus, a question arises, how to qualify the coordinates of corners of buildings with the use of the NP method in RTN GNSS survey technology, having applied the method of vector addition? The above mentioned differences are at the level of values which can be obtained by different contractors carrying out surveys of a building using tacheometry. Therefore, it may initially be assumed that the application of 
vector addition for the indirect method of measurement $N P$ allows not only to obtain consistency of tie distances, but also the most probable coordinates $\mathrm{X}$ and Y. However, it should definitely be emphasized once again, that such a situation is greatly influenced by the use of an open frame tape measure to define the baseline relative to the point of which is being determined. A properly placed open frame tape measure is a certain and clearly defined reference (baseline) for the method of a point on the straight line, which minimizes the error of setting out the base point (from RTN GNSS survey) to a straight line. However, since the $P P$ method requires some modernization in order to determine the most probable coordinates $\mathrm{X}$ and $\mathrm{Y}$, these tests could also cover the $N P$ method in order to further minimize the coordinate differences in the relationships of the methods $T-N P$.

Similarly, as in the case of tie distances, also in the analysis of the obtained coordinate differences (regardless of the indirect method of measurement), there are no legally sanctioned extremes which can be reached by the measurement results. Nevertheless, when seeing the values of coordinate differences at the level of several centimeters - the PP method - the results obtained in this way should be treated skeptically. On the other hand, the results of measurements of the buildings in the RTN GNSS mode using the NP method, after taking into account vector addition, should be expected with great optimism.

The last issue to consider is the accuracy of determining the position of the corner of a building, depending on the indirect method of measurement which was used, in RTN GNSS survey technology. This issue was thoroughly analyzed in (Krzyżek, 2014). It concerned indirect methods of measurement used in RTN GNSS surveys, without the use of the method of vector addition. However, the use of modified methods of measurement $(P P$ and $N P)$ does not affect significantly the value of the mean position error of a point which is being determined. Modernization of indirect methods of measurement involving vector addition changes the mean error $m_{P}$ of the position of a corner of a building by a few millimeters, at most. This is conditioned by the influence of the minimum values of the vectors $a$ and $b$ in the algorithm of the error propagation law, used to assess the accuracy of the position of corners of a building.

\section{SUMMARY AND CONCLUSIONS}

The use of indirect methods of measurement in the implementation of determining the position of a building with RTN GNSS survey technology is undoubtedly a very important and necessary direction of improving modern measurement techniques. As any emerging new technological solution introducing changes to the existing ones, it has its advantages and disadvantages. As a result of surveys of a building in RTN GNSS mode using indirect methods of measurement, the position of a structure is determined, but, unfortunately, with probability of committing significant measurement errors which, ultimately, deform the shape and the true position of the building. Only the method of distance-distance intersection gives positive results, equivalent in terms of accuracy to tacheometry (Krzyżek, 2014). The other two methods - a point on a straight line and intersection of straight lines - require significant modifications in order to ensure the reliability of the determined points (corners of a building). For this purpose, an innovative method called vector addition was introduced to the direct measurement results obtained from the use of the two above-mentioned indirect methods. The method of vector addition ensures full consistency of tie distances calculated from coordinates relative to the actual field surveys. However, for the method of vector addition to fulfill its functions in the practical implementation of measurements of details which are difficult to access, a certain process of field task automation (applications in GNSS receivers) should be developed, which after check measurements (of tie distances), would allow for quick and accurate adjustments of measurement results in real time. Full geometric 
consistency of a building is only a partial success in bringing indirect methods of measurement to the results reflecting the actual position of a structure in the field and on the map. The second problem which still remains to be solved is verifying the coordinates of the corners of a building after the application of the method of vector addition in such a way, so that their values were of the most probable character. The method of intersection of straight lines is the one which definitely requires such procedures. The coordinates of the corners of a building after the application of the method of vector addition still significantly deviate from those considered to be the most probable ones. One of the main reasons are the angles resulting from the intersection of straight lines at the points which are the corners of buildings. Although it definitely should be emphasized that not every angle of the apex in the corner of a building, and the shoulders forming the external faces of the building walls, is a right angle, but the a priori assumption of such a value of the angle $\left(90^{\circ}\right)$ is justified, and is considered already at the design stage of a building (the most common situation). Unfortunately, as a result of various factors having a direct or indirect influence on this angle in the field, its value often deviates from the nominal one. This aspect can and should be one of the attributes to be verified in the process of a comprehensive modernization of the method of intersection of straight lines.

On the other hand, the method of a point on the straight line, taking into account vector addition, remains a subjective and somewhat problematic aspect for the correct interpretation of the definitive values of the coordinates. On the one hand, the average values of the calculated coordinate differences by the methods $T-N P$ (small differences) and verification of the hypotheses which were made would suggest the classification of the obtained coordinates as definitive, that is the most probable ones. On the other hand, the ranges of these differences are at the level of a half of the error of a detail of the first-order accuracy, and thus, depending on the expected accuracy of the measurement results, in some circumstances they give at least the basis for limited confidence of the obtained values as definitive ones. In conclusion, the modernized method of a point on a straight line should be considered as strongly and positively correcting the obtained raw measurement results. However, in order to increase reliability in determining the most probable coordinates of the corners of a building, the method of a point on a straight line may be subjected to still further modifications, leading to even greater reliability of the results. Studies to modernize the methods of a point on a straight line and intersection of straight lines for the $\mathrm{X}$ and $\mathrm{Y}$ coordinates to be the most probable ones have become the subject of the author's further research.

Acknowledgments: This work was carried out within the statutory studies of the AGH University of Science and Technology, Faculty of Mining Surveying and Environmental Engineering No. 11.11.150.006.

\section{REFERENCES:}

Angrisano A., Gaglione S., Gioia C. (2013). Performance assessment of GPS/GLONASS single point positioning in an urban environment. Acta Geodaetica et Geophysica, Vol. 48, Issue 2, 149-161.

Bakuła M. (2013). Study of Reliable Rapid and Ultrarapid Static GNSS Surveying for Determination of the Coordinates of Control Points in Obstructed Conditions. Journal of Surveying Engineering, Vol. 139, No. 4, 188-193.

Beluch J., Krzyżek R. (2005). GPS RTK technology used for indirect methods of topographical surveys. Technical Sciences. Supplement/University of Warmia and Mazury in Olsztyn, suppl. 2, 47-60. 
Figurski M., Bogusz J., Bosy J., Kontny B., Krankowski A., Wielgosz P. (2011). "ASG+": project for improving Polish multifunctional precise satellite positioning system, Reports on Geodesy, Vol. 2 No. 91, 51-57.

Ge L., Lee I. (2006). The performance of RTK GPS for surveying under challenging environmental conditions. Earth, Planets and Space, Vol. 58, Issue 5, 515-522.

Krzyżek R. (2014). Reliability analysis of the results of RTN GNSS surveys of building structures using indirect methods of measurement. Geodesy and Cartography, Vol. 63, no. $2,161-181$.

Krzyżek R. (2013). Verification of applicability of the Trimble RTX satellite technology with $\mathrm{xFill}$ function in establishing surveying control networks. Geodesy and Cartography, Vol. 62 , no. 2, 217-233.

Krzyżek R. (2015). Modernization of the method of line-line intersection using RTN GNSS technology for determining the position of corners of buildings. Artificial Satellites, Journal of Planetary Geodesy, Vol. 50, no. 1, 41-57.

Kowalczyk K. (2011). Analysis of the errors generated during the measurement of situational details RTK GPS method. Acta Scientiarum Polonorum Geodesia et Descriptio Terrarum, $10(1), 5-22$.

Kowalczyk K. (2011). Evaluation of usefulness of measurements of inaccessible points using GPS RTK method with consideration of base errors. Przeglad Geodezyjny, 10, 7-12.

Leonardo R., Landau H., Nitschke M., Glocker M., Seeger S., Chen X., Deking A., Ben Tahar M., Zhang F., Ferguson K., Stolz R., Talbot M., Lu G., Allison T., Brandl M., Gomez V., Cao W., Kipka A., Trimble Terrasat GmbH Germany. (2011). RTX Positioning: The next generation of cm-accurate Real-Time GNSS Positioning. White Paper_RTX.

MIA. (2011). Regulation of Minister of Interior and Administration - in case of technical standards of performing detailed surveys and working out and sending results of these surveys to National Geodetic and Cartographic Database (in Polish). Journal of Laws of 2011 No. 263, entry 1572. Warsaw: Government Legislation Centre.

Paziewski J., Krukowska M., Wielgosz, P. (2014). Preliminary results on performance of new ultra-fast static positioning module - POZGEO-2 in areas outside the ASG-EUPOS network, Geodesy and Cartography, Vol. 63, no. 1, 101-109.

Pelc-Mieczkowska R. (2012). Analysis of GPS/RTK positioning reliability in hard observational conditions. Zeszyty Naukowe Politechniki Rzeszowskiej, z. 59 (1/II), 217226.

Pirti, A., Yucel, M. \& Gumus, K. (2013). Testing Real Time Kinematis GNSS (GPS and GPS/GLONASS) methods in obstructed and unobstructed sites, Geodetski Vestnik Vol. 57, no. 3, 498-512.

Teng Y., Wang J. (2015). A closed-form formula to calculate geometric dilution of precision (GDOP) for multi-GNSS constellations. GPS Solution, 10 February.

Zhang X., Li P. (2014). Integrating GPS and GLONASS to accelerate convergence and initialization times of precise point positioning. GPS Solution, Vol. 18, Issue 3, 461-471.

Received: 2015-08-18,

Reviewed: 2015-11-04,

Accepted: 2015-11-09. 